\title{
Nuclear import of doublecortin points to anticancer target in glioblastoma
}

\author{
Abiola Abdulrahman Ayanlaja \\ Guanquan Ji \\ Jie Wang \\ Yue Gao \\ Bo Cheng \\ Kouminin Kanwore \\ Lin Zhang \\ Ye Xiong \\ Piniel Alphayo Kambey \\ DianShuai Gao
}

\section{Video Byte}

Keywords: doublecortin, nuclear translocation, nucleus, cell biology, microtubule associated protein, MAP, neurogenesis, migration, neuron, glioma, cancer, confocal microscopy, imaging, CRISPR, RanGTPase, signaling, therapy

Posted Date: October 29th, 2020

DOI: https://doi.org/10.21203/rs.3.rs-100312/v1

License: (c) (i) This work is licensed under a Creative Commons Attribution 4.0 International License. Read Full License 


\section{Abstract}

Despite advances in therapy, the prognosis and survival of patients with glioblastoma remain dismal. Part of the reason is poor targeting. The sheer complexity of tumor growth at the molecular scale makes it difficult to pinpoint the origin of gliomas. In recent years, more targeted research has led to the discovery of chains of molecular events that regulate glioma development, including the unusual trafficking of proteins into the nucleus of glioma cells. In a new study, researchers examined this gliomarelated behavior for the protein doublecortin (DCX). DCX is a neuronal protein crucial for the formation of new neurons in adulthood and for neuronal migration. While researchers have looked at how glioma cells shuttle different proteins to their nucleus, this marked the first time that scientists zeroed in on DCX. The team found that high accumulation of DCX in the nucleus boosted the invasiveness of glioma cells, whereas blocking the nuclear import of DCX reduced glioma proliferation. These findings could point to a weakness in glioma development that researchers can exploit in designing anticancer drugs. 